\author{
관군 배열에서의 종간 간격이 \\ 열전달에 미치는 영향에 대한 수치 해석적 연구 \\ 이 동 균, ${ }^{1}$ 안 준, ${ }^{2}$ 신 승 원 ${ }^{* 3}$

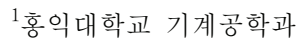 \\ 2국민대학교 기계 시스템 공학부 \\ ${ }^{3}$ 홍익대학교 기계 - 시스템 디자인공학과
}

\title{
Numerical ANAlysis fOR LONGITUdinal Pitch EFFect ON TUbE BANK HeAT TRANSFER
}

\author{
D. Lee, J. Ahn ${ }^{2}$ and S. Shin ${ }^{* 3}$ \\ ${ }^{1}$ Dept. of Mechanical Engineering, Hongik Univ. \\ ${ }^{2}$ School of Mechanical Systems Engineering, Kookmin Univ. \\ ${ }^{3}$ Dept. of Mechanical and System design Engineering, Hongik Univ.
}

\begin{abstract}
In this study, a longitudinal pitch effect on in-line tube bank heat transfer has been analyzed numerically. To verify the accuracy of the solver model and boundary conditions, global Nusselt number(Nu) and pressure drop across the 2 row tube bank are compared with the existing experimental correlations under $500 \sim 2,000$ Reynolds number $(R e)$ range. By changing transverse pitch $\left(S_{T}\right)$ or longitudinal pitch $\left(S_{L}\right)$ separately in tube bank, we're trying to identify the each effect on heat transfer. We found that the effect of transverse pitch can be accounted for Reynolds number evaluated with maximum velocity $\left(V_{\max }\right)$ at the smallest flow area similar to most existing correlations. Variation of the longitudinal pitch $\left(S_{L}\right)$ has a greater impact on the heat transfer compared to the transverse pitch $\left(S_{T}\right)$. Overall Nusselt number increases with larger longitudinal pitch $\left(S_{L}\right)$, however individual Nusselt number of the tube row has significant difference after the first row.
\end{abstract}

Key Words : 수치 해석(Numerical Analysis), 관군(Tube Bank), 열전달 계수(Heat Transfer Coefficient),

압력 강하(Pressure Drop), 횡간 간격(Transverse Pitch), 종간 간격(Longitudinal Pitch)

\section{1. 서 론}

에너지 재활용에 대한 연구가 활발히 진행됨에 따라 열병 합 발전 시스템의 사용이 증가하고 있으며 대형 빌딩이나 병 원, 위락 시설 등에서는 추가적으로 소형 열병합 발전 시스템 을 설치하여 비상시 전력 수급을 위해 사용하고 있다. 근래에 는 이러한 시설 등에서 전력뿐만 아니라 고온의 증기를 필요

Received: February 15, 2012, Revised: August 24, 2012, Accepted: August 27, 2012.

* Corresponding author, E-mail : sshin@wow.hongik.ac.kr DOI http://dx.doi.org/10.6112/kscfe.2012.17.3.039

(C) KSCFE 2012
로 함에 따라 발전 시스템 내부에 폐열을 재활용하여 증기를 얻을 수 있는 HRSG (Heat Recovery Steam Generator) 시스템 을 도입하여 그 효율을 극대화 시키려고 노력하고 있다. HRSG 시스템에 대한 간단한 개략도를 Fig. 1에서 확인할 수 있다. 그림에서 볼 수 있듯이 시스템 내부에 설치된 여러 모 듈의 증발관을 흐르는 물은 발전 시스템으로부터 배출된 가 스와 차례로 열교환을 이룬다. 증발관 내부에서 열교환을 이 룬 물은 증기로 변화하며 상승하여 증기 수집 장치로 수집된 후 필요한 곳으로 공급된다. 여기서 증발관의 배열은 제한된 공간 안을 지나는 배기 가스의 유동 단면적에 직접적인 영향 을 주어 유동 형태를 변화시킬 수 있는 중요한 요인이 되며 이는 곧 배기 가스와 증발관 내부를 흐르는 물과의 열교환 성능에 매우 큰 영향을 미치게 된다. 또한 적절한 설계를 통 


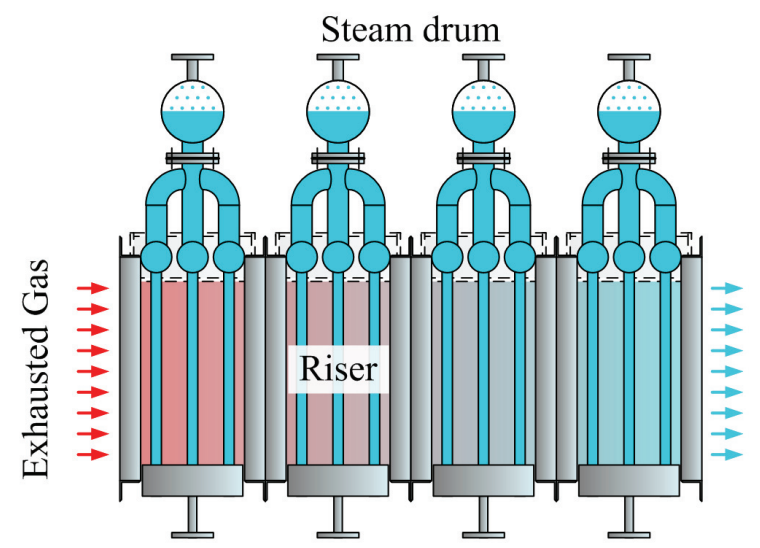

Fig. 1 Schematic diagram of heat transfer module in HRSG system

해 설치 면적을 최소화 시킬 수 있다면 설치 비용 또한 줄일 수 있으므로 이러한 열교환기의 정확한 설계는 효율적이고 경제적인 사용을 위해 반드시 선행되어야 한다. 이를 위해 관 사이의 간격이 유동 형태와 열전달 성능에 어떤 영향을 미치 는 지에 대한 정확한 이해가 필요하며 지금까지 이에 대한 많은 연구가 실험적, 수치 해석적인 방법을 통해 진행되어 왔 다.

Hilpert[1], Jakob[2], Fand[3], Sanitjai[4], Churchill과 Bernstein[5]은 실험을 통해 하나의 관에 대한 공기의 직교 유 동에서 레이놀즈 수와 누셀 수의 상관 관계식을 도출하였다. Grimison[6]은 정렬 및 엇갈림 배열로 배치된 관군에서 관 사 이의 특정 간격에 따라 이를 지나는 유동의 레이놀즈 수와 누셀 수의 상관식을 도출하였으며 Zhukauskas[7]는 보다 광범 위한 레이놀즈 영역에서 관군을 지나는 직교 유동의 레이놀 즈 수에 따른 누셀 수 및 압력 강하에 대한 관계식을 실험적 인 방법을 통해 도출하였다. 열교환시 관군 유동의 효용성이 뛰어나고 그 활용 범위가 광대해짐에 따라 시간과 비용을 단 축하고 실험으로 확인하기 힘든 특별한 경우의 해석을 위해 수치 해석적인 방법을 통한 연구도 시행되어 왔다. Zdravistch[8]등은 RANS 방정식을 사용하여 층류 및 난류 유 동의 열전달 성능을 계산할 수 있는 수치 방법을 제시하였고 $\operatorname{Fan}[9]$ 등은 기체가 엇갈림 배열을 갖는 부식된 관군을 지날 때의 유동을 수치적인 방법으로 해석하였다.

관군 주변의 유동 면적이 관 사이의 횡간 간격(유동 방향 에 수직한 방향의 관 간격, $\mathrm{S}_{\mathrm{T}}$ in Fig. 2)을 통해 결정되고 열 전달 성능 또한 유동 면적에 의해 많이 좌우되므로 지금까지 진행된 대부분의 연구들이 횡간 간격의 영향에 초점을 맞춰 자세히 수행되었으며 종간 간격(유동 방향과 나란한 방향의 관 간격, $\mathrm{S}_{\mathrm{L}}$ in Fig. 2)에 의한 영향은 몇몇 특별한 경우에 대 해서만 연구되었다. 하지만 Fig. 1에 나타낸 HRSG 시스템의

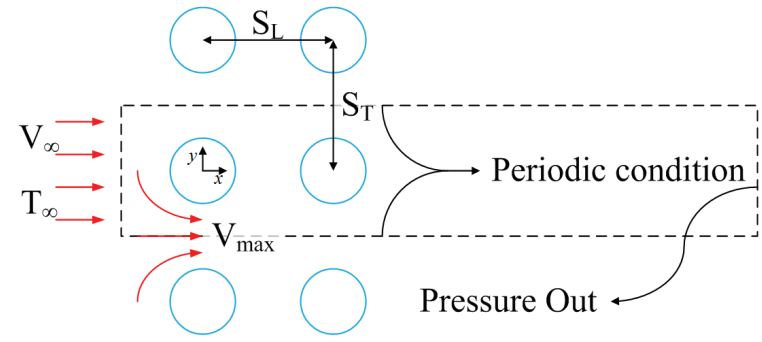

Fig. 2 Computational domain and boundary conditions

경우 여러 개의 모듈화 된 관군을 허용 면적에 맞게 설치하 는 경우가 대부분이고 이러한 경우에 효과적인 설계를 위해 서는 다양한 종간 간격 배열을 갖는 관군에 대해 열전달 성 능을 정확하게 예측할 수 있는 도구가 필요하지만 현재까지 는 이에 대한 연구가 많이 부족한 상황이다.

따라서 본 연구에서는 횡간, 특히 종간 간격이 관군의 열 전달 성능에 미치는 영향을 파악하고자 상용 전산 유체 해석 프로그램인 Fluent를 사용하여 수치 해석적인 방법으로 다양 한 배열에 대한 분석을 수행하였다. 기존 연구 결과와의 비교 를 통해 해석 모델 및 경계 조건에 대한 신뢰성을 검증하였 으며 검증한 해석 모델을 통해 2개 이상의 열을 갖는 관군에 대해 분석을 실시하여 횡간 및 종간 간격이 관군 열전달에 미치는 영향을 확인하였다.

\section{2. 수치 해석}

본 연구에서는 수치 해석 결과의 정확성을 확인하기 위해 열의 개수가 두 개인 경우에 대해 Grimison[6], Zhukauskas[7], Safwat[10]의 실험 결과와 비교하여 해석 모델 및 경계 조건 의 타당성을 검증하였고 종간 및 횡간 간격의 영향을 확인하 기 위해 열의 개수가 세 개인 경우에 대해 변수 분석을 실시 하였다. 계산은 500 에서부터 2,500 레이놀즈 영역에서 수행하 였고 이를 포함한 유동 조건 및 형상은 $\operatorname{Kim}[11]$ 등에 의해 수행된 $1 \mathrm{MW}$ 급 소형 열병합 발전 시스템에 사용되는 핀튜브 증발기의 모듈별 특성실험의 제원을 참고하여 결정하였다.

\section{1 모델 형상 및 경계 조건}

본 연구에서의 검증 과정과 변수 분석을 위한 수치해석은 Fig. 2와 같이 2차원 계산 영역에서 수행되었다. 계산 영역의 $\mathrm{y}$ 방향 길이는 관군의 횡간 간격이며 관의 직경(D)은 $5 \mathrm{~cm}$ 이 고 표면 온도는 관 내부의 물이 5 기압 상태에서 상변화 함을 고려하여 $423.15 \mathrm{~K}$ 의 일정한 값을 갖도록 하였다. 입구 영역 의 온도는 $1123.15 \mathrm{~K}$ 이고 속도는 계산하고자 하는 레이놀즈 수에 맞게 계산하여 입력하였으며 출구 영역은 open condition 


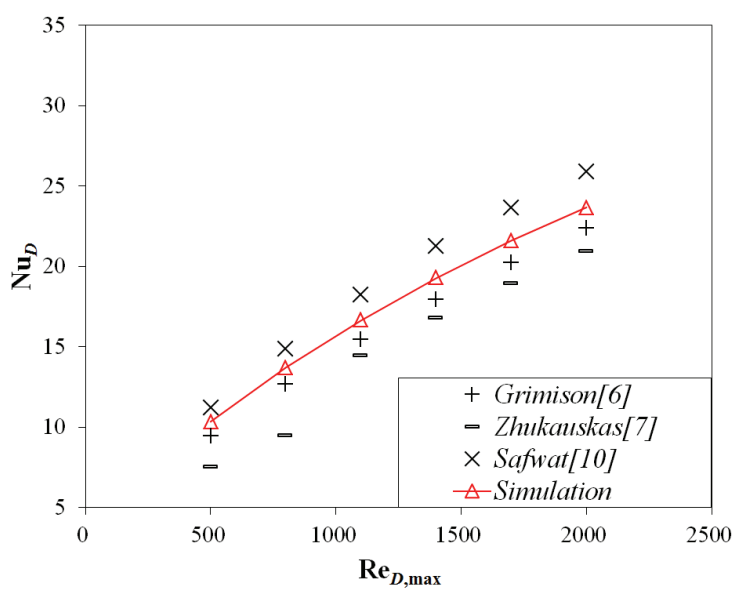

(a) Nusselt number distribution with different $\operatorname{Re}_{D, \max }$

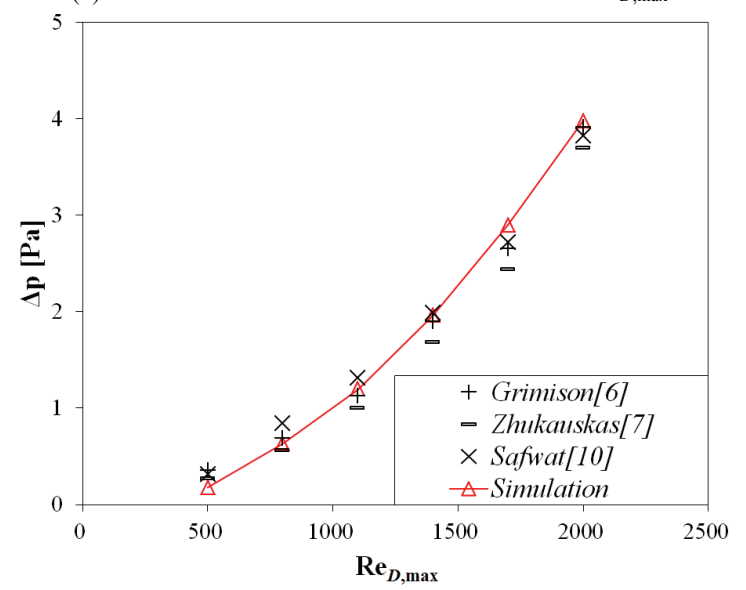

(b) Pressure drop distribution with different $\operatorname{Re}_{D, \max }$

Fig. 3 Comparison between the simulation results and different empirical correlations (2 row)

으로 설정하였다. 후류 영역의 길이는 출구 영역의 영향을 받 지 않도록 직경의 13 배로 설정하였으며 윗면과 아랫면의 경 계 조건은 실제 위 아래에 관이 배열되어 있음을 고려하여 주기 조건으로 설정하였다. 또한 대부분의 관군 유동에서와 마찬가지로 본 연구에서 사용하는 모든 레이놀즈 수를 유동 단면적이 가장 적은 구간에서 계산되는 최대 속도 $\left(\mathrm{V}_{\max }\right)$ 로부 터 평가하였다.

\section{2 수치해석 방법 및 검증}

2차원 모델의 계산을 위한 지배 방정식으로 비압축성 유체 에 대한 연속, 운동량, 에너지 방정식을 사용하였고 격자계는 Lee[12] 등이 수렴성을 확인한 기존의 연구를 참고하여 최대 900,000 개의 사각형 격자로 구성하였다. 난류 모델로는 관에 의해 생긴 길이 차원이 지배적일 것으로 판단하여 $\mathrm{RNG} \mathrm{k- \varepsilon}$
모델을 사용해 정확성을 확인하였고 Fig. 3에서 확인 할 수 있듯이 압력변화가 매우 적은 반면, 저온부와 고온부의 온도 차이가 $700 \mathrm{~K}$ 으로 매우 크기 때문에 온도에 따른 열 물성의 변화를 고려하였다. 밀도를 제외한 물성치들은 $100 \mathrm{~K}$ 의 간격 으로, 전체 온도 범위를 9 구간으로 나누어 선형적으로 보간 되도록 하였다. 밀도의 경우 매우 저속에서 작동하고 있기 때 문에 비압축성유체를 적용하였다. 연소가스가 충분히 높은 온 도에 있으므로 이상기체로 가정할 수 있고, 이상기체 상태방 정식 중 압력을 대기압으로 고정하는 경우 밀도는 온도만의 함수(FLUENT에서 Incompressible ideal gas law 조건 사용)가 되고, 이를 이용하여 밀도의 온도에 따른 변화를 고려하였다.

해석 모델 및 경계조건의 신뢰도 검증을 위해 Fig. 1과 같 이 열의 개수가 두 개일 때 횡간 간격과 종간 간격의 비 $\left(\mathrm{S}_{\mathrm{T}} / \mathrm{S}_{\mathrm{L}}\right)$ 가 1 이면서 직경과의 비 $\left(\mathrm{S}_{\mathrm{T}} / \mathrm{D}, \mathrm{S}_{\mathrm{L}} / \mathrm{D}\right)$ 가 1.5 인 경우에 대 해 레이놀즈 수를 500 에서 2,000까지 변화시켜가며 수치 해석 을 수행하였다. 입구와 출구 영역에서의 압력 강하 및 열전달 계수인 누셀 수를 기존에 연구된 상관 관계식을 통해 계산한 결과와 비교하였으며 결과는 횡간 간격과 관의 직경에 의해 계산되어지는 최대 레이놀즈 수 $\left(\operatorname{Re}_{D, \max }\right)$ 에 따라 나타내었다. 수치 해석을 통해 구해진 입구 영역과 출구 영역, 관의 표면 온도에 의한 LMTD(Log Mean Temperature Difference)를 통해 누셀 수를 계산하였으며 Fig. 3(a)에서 레이놀즈 수에 따른 누 셀 수의 분포를 확인할 수 있다. 수치해석 결과가 매우 작은 오차로 기존의 연구 결과들에 근접하는 것을 확인할 수 있으 며 Fig. 3(b)에 보인 압력 강하 또한 기존 연구 결과들과 매우 적은 오차 범위 안에서 계산되는 것을 확인할 수 있다. 따라 서 본 연구에서 설정한 수치 모델과 경계 조건으로 실제 현 상과 매우 근접한 결과를 얻을 수 있음을 확인하였다.

\section{3. 결과 및 고찰}

관 사이 간격이 열전달 성능에 미치는 영향을 확인하기 위 한 수치 해석은 다음과 같은 조건 하에서 수행하였다. 먼저 횡간 간격의 영향을 확인하기 위해 종간 간격을 $0.20 \mathrm{~m}$ 로 고 정 시긴 후 횡간 간격을 변화시켜가며 확인하였고 이를 제외 한 다른 변수들은 모두 일정하게 고정시켰으며 앞에서 언급 한 바 있는 $\operatorname{Kim}[11]$ 등이 실험했던 유동 조건을 참고하여 레 이놀즈 영역이 1,700 과 2,500 인 경우에 대해 수행하였다. Zhukauskas[7]의 연구 결과와 비교하기 위해 배기 가스가 모 든 관을 지난 후 전체 관에 대한 누셀 수를 구하였으며 그 결과를 Fig. 4 에서 확인할 수 있다. 기존 연구 결과와 같이 동 일한 레이놀즈 영역에서는 횡간 간격이 증가하더라도 누셀 수의 변화가 거의 없음을 수치 해석 결과에서도 확인할 수 있다. 하지만 레이놀즈 수는 유동 단면적이 가장 작은 구간에 


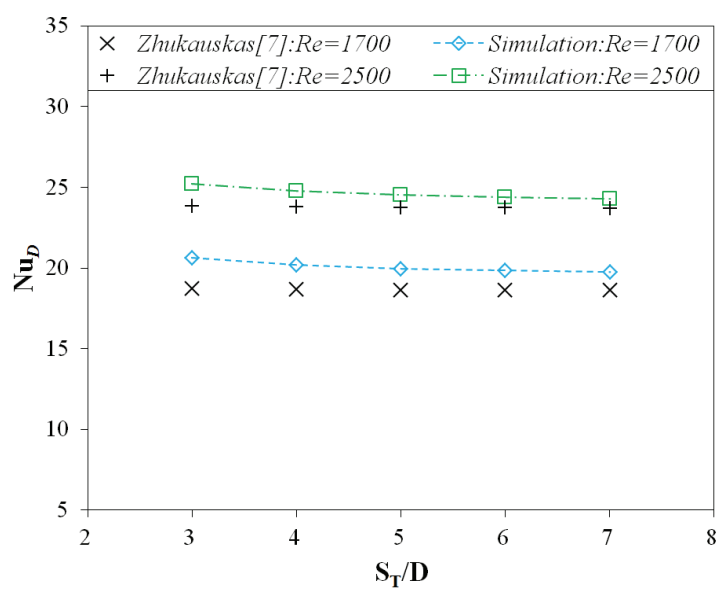

Fig. 4 Effect of transverse pitch on Nusselt number with different $\operatorname{Re}_{D, \max }$ (3 row)

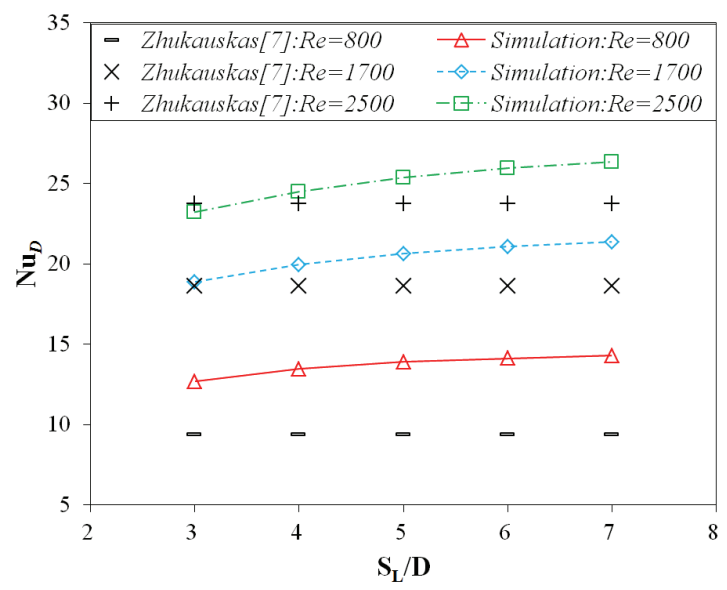

Fig. 5 Effect of longitudinal pitch on Nusselt number with different $\operatorname{Re}_{D \text {,max }}$ (3 row)

서 계산되는 최대속도에 의해 평가되며 이 단면적은 횡간 간 격의 영향을 직접적으로 받기 때문에 횡간 간격의 영향은 레 이놀즈 수의 변화에 함께 포함되어 있다고 볼 수 있다.

종간 간격이 열전달에 미치는 영향을 확인하기 위해 횡간 간격을 $0.25 \mathrm{~m}$ 로 고정시킨 후 종간 간격을 변화시키면서 계 산을 수행하였다. 앞에서와 같이 다른 변수는 일정하게 고정 시키고 $800,1,700$ 및 2,500 레이놀즈 영역에서 해석하였으며 그 결과를 Fig. 5에서 확인할 수 있다. 동일한 레이놀즈 영역 에서 종간 간격이 커질수록 누셀 수도 증가하는 것을 확인할 수 있으며 레이놀즈 영역이 증가할수록 누셀 수의 변화 폭도 함께 커지는 것을 확인할 수 있다. 또한 동일한 레이놀즈 영 역에서 임의의 값 이상으로 종간 간격이 커질 때 누셀 수는 거의 증가하지 않으며 일정한 값에 수렴해 가는 것을 확인할

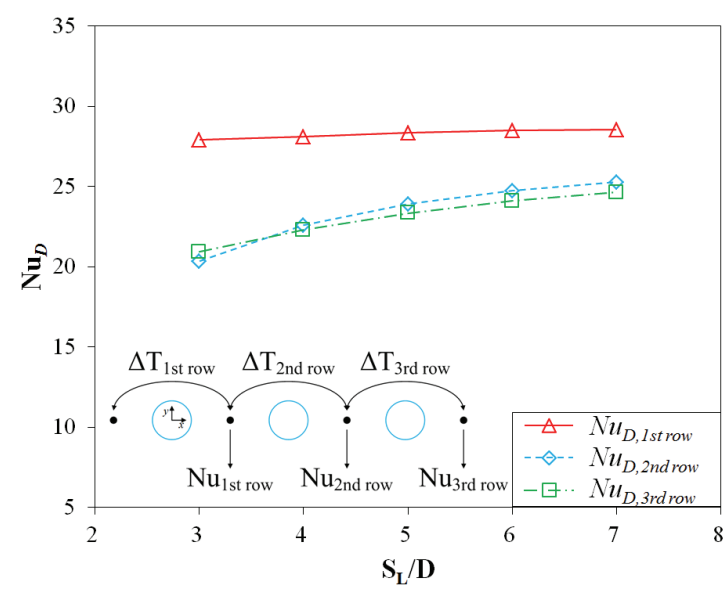

Fig. 6 Nusselt number variation along the each row with different longitudinal pitch $\left(\operatorname{Re}_{D, \max }=2,500\right.$ fixed $)$

수 있다. 각 열마다의 열전달 성능을 독립적으로 확인하기 위 해 Fig. 6에 나타낸 것과 같이 열을 지날 때마다 배기의 온도 차이를 측정하여 해당 열의 누셀 수를 각각 계산하였다. 첫 번째 열에서의 누셀 수는 하류에 배치된 다른 관들에 비해 상대적으로 큰 값을 가지며 종간 간격이 길어져도 큰 변화 없이 일정하게 유지되지만 두 번째 관과 세 번째 관에서의 열전달 계수는 첫 번째 관과는 일정한 차이를 가지며 비슷하 게 측정됨을 확인할 수 있다. 또한 종간 간격이 짧아질수록 열전달 성능이 떨어지고 종간 간격이 길어지면서 일정한 값 에 수렴해 가는 것을 볼 수 있다. 이를 통해 관의 상류에 존 재하는 정체 유동이 하류에 있는 정체 유동에 비해 열교환 성능에 큰 영향을 미친다는 것을 알 수 있으며 일정 길이 이 상의 종간 간격 배열을 갖는 관군에서 열교환 성능은 더 이 상 증가하지 않는 것을 확인할 수 있다.

이러한 현상은 Fig. 7과 Fig. 8에 나타난 온도 분포 및 속 도 분포를 통해 설명되어진다. 첫 번째 관을 통과한 유체의 온도는 Fig. 7 에서 확인할 수 있듯이 종간 간격에 영향을 받 지 않고 비슷한 값을 갖는다. 각 관을 통과한 유체의 온도는 종간 간격이 길어질수록 주변 유동에 의해 고온으로 회복하 게 되지만 간격이 짧은 경우 상대적으로 온도를 회복하지 못 한 상태에서 다음 관과의 열 교환이 이뤄진다. 따라서 각 관 을 지날 때마다 고온부와 저온부의 온도 차이가 감소하게 되 고 열전달량 또한 감소한다. 이러한 종간 간격에 따른 온도 분포는 Fig. 8 에 나타난 속도 분포와 밀접한 관련이 있다. 그 림에서 확인할 수 있듯이 동일한 레이놀즈 영역에서 종간 간 격의 길이가 짧아지면 상류에 배치된 관의 영향을 크게 받아 관 사이에서 유동이 정체되는 구간이 커지게 된다. 유동의 정 체는 대류를 통한 열교환에 직접적으로 영향을 미치고 열전 


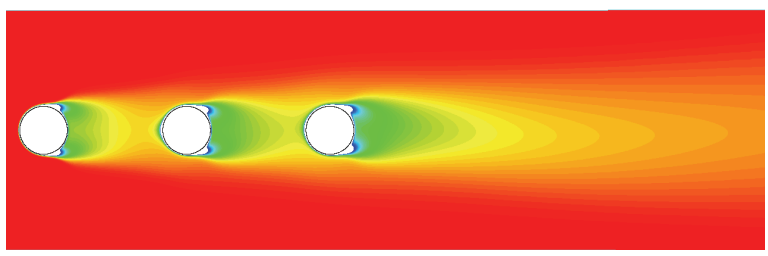

(a) $\mathrm{S}_{\mathrm{L}}=0.15 \mathrm{~m}$

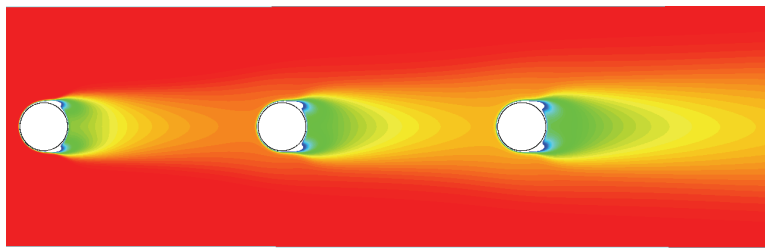

(b) $\mathrm{S}_{\mathrm{L}}=0.25 \mathrm{~m}$

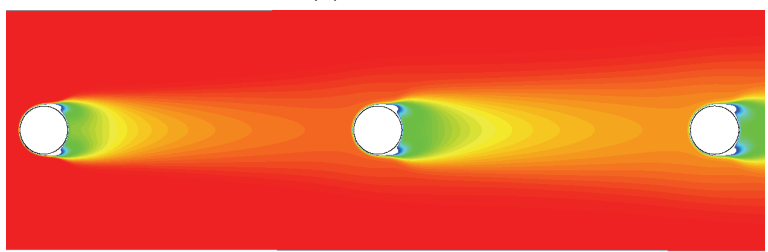

(c) $\mathrm{S}_{\mathrm{L}}=0.35 \mathrm{~m}$

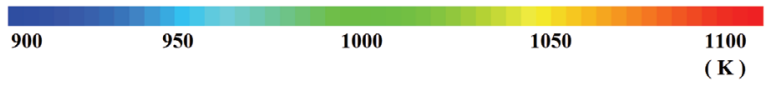

Fig. 7 Temperature contours with different longitudinal pitch under same $\operatorname{Re}_{D, \text { max }}\left(\operatorname{Re}_{D, \text { max }}=2,500\right)$

달 효율의 저하를 야기한다. 종간 간격이 길어질수록 열전달 성능이 증가하긴 하지만 그 길이가 너무 길어져 정체 구간이 사라지게 되고 유체의 흐름이 회복되면 열전달 효율은 더 이 상 증가하지 않는다. 따라서 그 이상 종간 간격을 증가시키면 설치 면적이 불필요하게 늘어나게 되므로 일정 길이 이상의 종간 간격은 열교환기로서 경제적 가치를 반감시키게 된다.

Fig. 9에 나타난 것과 같이 동일한 종간 간격을 갖는 경우 에 횡간 간격의 변화 없이 레이놀즈 수가 증가하면 관 사이 에서 유동의 정체 구간이 발달하지만 상대적으로 빠르게 지 나가는 주변 유동에 의해 온도 경계층이 얇게 형성되고 온도 구배가 커지게 된다. 이로 인해 열전달 계수가 증가하며 따라 서 형상의 변화 없이 레이놀즈 수가 증가할 때는 종간 간격 이 증가할 때보다 열전달 성능의 증가에 더 큰 영향을 미칠 수 있음을 확인할 수 있다. 반면 이러한 경우 평균 속도의 증 가로 인해 압력 손실이 증가하고 구동 비용 또한 증가하게 되므로 열교환기 설계 시에 이 점에 유념하여 설계할 필요가 있다.

\section{4. 결론 및 향후 연구 계획}

본 연구에서는 관군 유동에서 종간 간격의 변화가 열전달

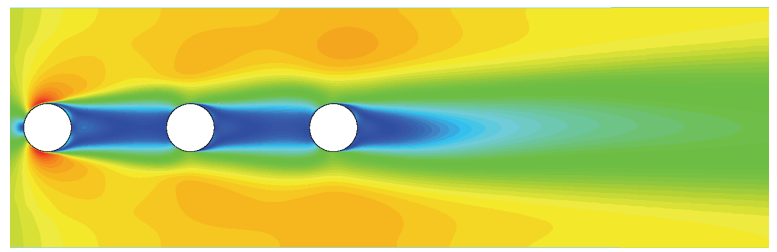

(a) $\mathrm{S}_{\mathrm{L}}=0.15 \mathrm{~m}$

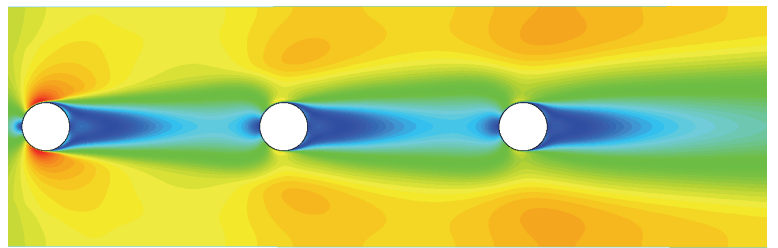

(b) $\mathrm{S}_{\mathrm{L}}=0.25 \mathrm{~m}$

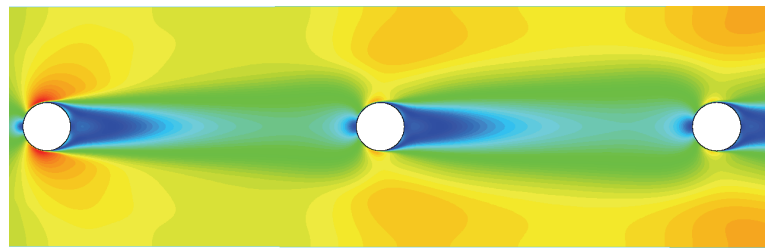

(c) $\mathrm{S}_{\mathrm{L}}=0.35 \mathrm{~m}$

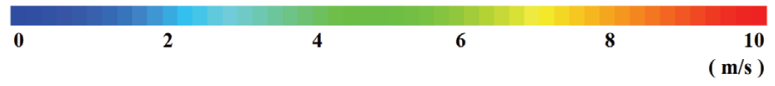

Fig. 8 Velocity contours with different longitudinal pitch under same $\operatorname{Re}_{D, \text { max }}\left(\operatorname{Re}_{D, \text { max }}=2,500\right)$

에 미치는 영향을 확인하기 위하여 상용 소프트웨어인 Fluent 를 사용하여 수치 해석을 수행하였다. RNG k- $\varepsilon$ 난류 모델로 500 에서 2,000 레이놀즈 영역에 대해 해석한 후 기존에 연구 된 실험 관계식들로 구한 누셀 수와 압력 강하 결과의 비교 를 통하여 2 차원 수치 모델의 신뢰성을 확인하였으며 계산 시간을 단축시키기 위해 출구 조건의 영향을 받지 않는 범위 에서 가장 짧은 후류 영역의 길이를 찾아 적용하였다.

동일한 레이놀즈 영역에서 다양한 횡간 간격에 대해 누셀 수의 분포를 분석한 결과 최대 속도를 통해 레이놀즈 수를 정의하는 경우에는 횡간 간격의 효과가 포함되어 있음을 확 인하였다. 종간 간격에 대한 분석 결과 기존의 연구 결과와는 다르게 종간 간격이 길어질수록 누셀 수도 증가하는 것을 확 인할 수 있었다. 하지만 이러한 누셀 수의 증가는 각 레이놀 즈 영역마다 일정한 종간 간격 영역에서만 이루어지며 종간 간격의 길이가 직경의 약 7 배 이상으로 길어지면 열전달 성 능에는 거의 영향을 미치지 않음을 확인할 수 있었다. 반면 형상이 일정할 때 레이놀즈 수가 증가하면 상대적으로 빠른 주변 유동에 의해 평균 열전달 계수가 증가하는 것을 확인하 였다.

본 연구를 통해 기존의 상관 관계식으로는 예측할 수 없었 던, 종간 간격이 열전달에 미치는 영향을 확인하였으며 그 길 


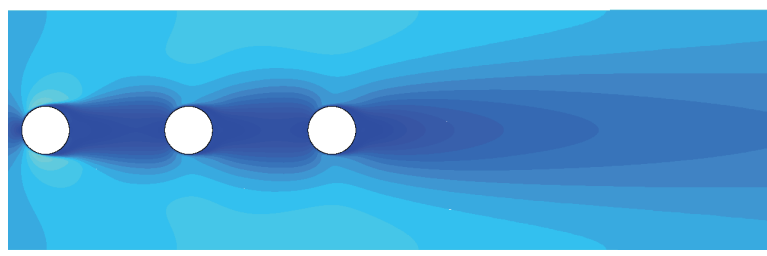

(a) $\operatorname{Re}_{D, \max }=800$

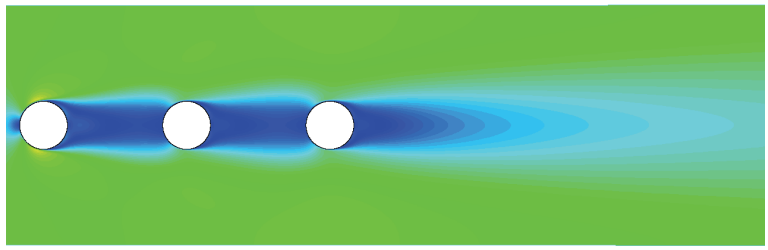

(b) $\operatorname{Re}_{D, \max }=1,700$

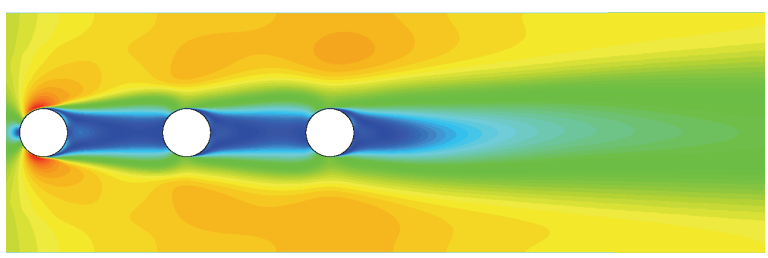

(c) $\operatorname{Re}_{D, \max }=2,500$

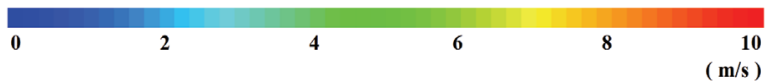

Fig. 9 Velocity contours with different $\mathrm{Re}_{D, \max }$ under same longitudinal pitch $\left(\mathrm{S}_{\mathrm{L}}=0.15 \mathrm{~m}\right)$

이에 따라 변화 폭도 달라지는 것을 확인하였다. 하지만 앞에 서 말한 것과 같이 실제 사용되는 보일러나 열 회수 장치에 서는 불균일한 종간 간격이 활용되는 경우가 있기 때문에 보 다 정확히 예측하기 위해 다양한 수치해석을 통한 분석이 필 요하며 현재 이러한 과정이 진행 중에 있다.

\section{참고문헌}

[1] 1933, R. Hilpert, "Wärmeabgabe von Geheizten Drähten und Rohren im Luftstrom," Forsch. Geb. Ingenieurwes, Vol.40, pp. 220.

[2] 1938, M. Jakob, "Heat Transfer and Flow Resistance in Cross Flow of Gases Over Tube Banks," Trans. ASME,
Vol.60, pp.384.

[3] 1965, R.M. Fand, "Heat Transfer by Forced Convection from a Cylinder to Water in Cross Flow," Int. J. Heat. Mass. Transf., Vol.8, pp.995.

[4] 2004, S. Sanitjai and R.J. Goldstein, "Forced Convection Heat Transfer From a Circular Cylinder in Cross Flow to Air and Liquids," Int. J. Heat. Mass. Transf., Vol.47, pp.4795-4805.

[5] 1977, S.W. Churchill and M. Bernstein, "A Correlating Equation for Forced Convection from Gases and Liquids to a Circular Cylinder in Cross Flow," J. Heat. Transf., Vol.99, pp.300-306.

[6] 1937, E.D. Grimison, "Correlation and Utilization of New Data on Flow Resistance and Heat Transfer for Cross Flow of Gases Over Tube Banks," Trans. ASME, Vol.59, pp.583-594.

[7] 1972, A. Žukauskas, "Heat Transfer from Tubes in Cross Flow," Adv. Heat Transf., Vol.8, pp.93-160.

[8] 1995, F. Zdravistch, C. Fletcher and M. Behnia, "Numerical Laminar and Turbulent Fluid Flow and Heat Transfer Predictions in Tube Banks," Int. J. Num. Meth. Heat Fluid Flow, Vol.5, pp.717-733.

[9] 1994, J. Fan, D. Zhou, Q. Hua and K. Cen, "Numerical Computation of Particle Laden Gas Flows Past Staggered Tube Banks Undergoing Erosion," Powder Tech., Vol.80, pp.1-10.

[10] 2000, A.S. Wilson and M.K. Bassiouny, "Modeling of Heat Transfer for Flow Across Tube Banks," Chem. Eng. Proc. Vol.39, pp.1-14.

[11] 2008, Kim, J.J., Choi, K.S., Ki, H.C. and Kang, S.B., "Experimental Study on Thermal Characteristics of Heat Exchanger Modules for Multi Burner Boiler - Part Load Test Results," Proceeding of SAREK 2008 Summer Annual Meeting, pp.1025-1030.

[12] 2010, Lee, D.G. and Shin, S.W., "Validation of Grid and Boundary Conditions for Optimal Design of Heat Recovery System," Proceeding of KSCFE 2011 Spring Annual Meeting, pp.608-609. 